\title{
Intercepting psoriatic arthritis in patients with psoriasis: buy one get one free?
}

\author{
Dennis G McGonagle, ${ }^{1,2}$ Alen Zabotti (D) ,' Abdulla Watad (D) , \\ Charlie Bridgewood, ${ }^{1,2}$ Gabriele De Marco, 1,2 \\ Andreas Kerschbaumer (D), ${ }^{5}$ Daniel Aletaha (i) ${ }^{5}$
}

Psoriatic arthritis (PsA) mostly develops in patients with an established diagnosis of psoriasis (PsO). ${ }^{1}$ Following the onset of PsA, structural articular damage and loss of function often occur, leading to impairment in quality of life above and beyond that seen in $\mathrm{PsO}$ alone. ${ }^{2} \mathrm{PsO}$ registry studies show a progression to PsA in around $1.5 \%-3 \%$ per year in PsO subjects, although figures may be even higher when

\footnotetext{
'University of Leeds, Leeds Institute of Rheumatic and Musculoskeletal Medicine, Leeds, UK

${ }^{2}$ Leeds Teaching Hospitals NHS Trust, NIHR Leeds

Biomedical Research Centre, Leeds, UK

${ }^{3}$ Department of Medical and Biological Sciences, Institute of Rheumatology, University Hospital Santa Maria della Misericordia, Udine, Italy

${ }^{4}$ Department of Medicine 'B, Rheumatology Unit, Zabludowicz Center for Autoimmune Diseases, Sheba Medical Center, Tel-Hashomer, Israel

${ }^{5}$ Department of Medicine III, Division of Rheumatology, Medical University of Vienna, Vienna, Austria
}

Correspondence to Prof. Dennis G McGonagle, Chapel Allerton Hospital, University of Leeds Leeds Institute of Rheumatic and Musculoskeletal Medicine, Leeds, LS2 9JT, UK; d.g.mcgonagle@leeds.ac.uk
PsO associates with other factors (eg, arthralgia). ${ }^{3}$ Reducing this rate of PsA development and identifying PsO subjects at higher risk for PsA progression is of paramount importance, especially given that many PsO therapies have been independently verified as being efficacious for established PsA. Therefore, by extension, these therapies might also be expected to work at the earliest stages of PsOassociated inflammatory arthritis, where better therapeutic effectiveness is generally expected. ${ }^{4}$

The ability to characterise the preclinical phases of autoimmune diseases, as initially in type 1 diabetes (T1DM), ${ }^{5}$ was followed by other diseases, including rheumatoid arthritis (RA) ${ }^{6}$ or autoimmune connective tissue diseases. ${ }^{7}$ They provide the unique window of opportunity for therapeutic interventions in the preclinical stage of disease. Interventions applied at this point, as the hypothesis goes, would minimise disease burden and subsequent irreversible joint damage leading to functional impairment and long-term disability, eventually to reducing the complications and socioeconomic impact of disease. Historically, the prevention of diseases, such as T1DM, for example, with cyclosporine, was marred by incomplete responses and drug toxicity. ${ }^{8}$ Nonetheless, proof of concept for disease prevention was established. In this editorial, we discuss emerging and conflicting evidence about early stage therapy for PsA. Specifically, we will explore the concept of prescription of disease-modifying antirheumatic drugs (DMARDs), including biological DMARDs (bDMARDs), in subjects with moderate-to-severe PsO, at no extra cost to the health payers and no additional risk for patients, and the related impact on the interception of the evolution of PsO to PsA (figure 1A,B). We dubbed this approach 'buy one, get one for free', as beneficial effects on one manifestation of psoriatic disease would result from interventions prescribed to treat other, different signs or symptoms.

Predictive markers for inflammatory disease development usually focus on laboratory biomarkers, like anticitrullinated protein antibodies used in RA (positive in $70 \%$ of cases). However, rather than laboratory tests in PsA the most relevant biomarker seems to be the clinical presentation of $\mathrm{PsO}$ itself, as present in $70 \%$ of subjects who will subsequently develop PsA. ${ }^{2}$ This aspect of PsA disease interception is unique compared with other immunemediated disorders prevention, where 

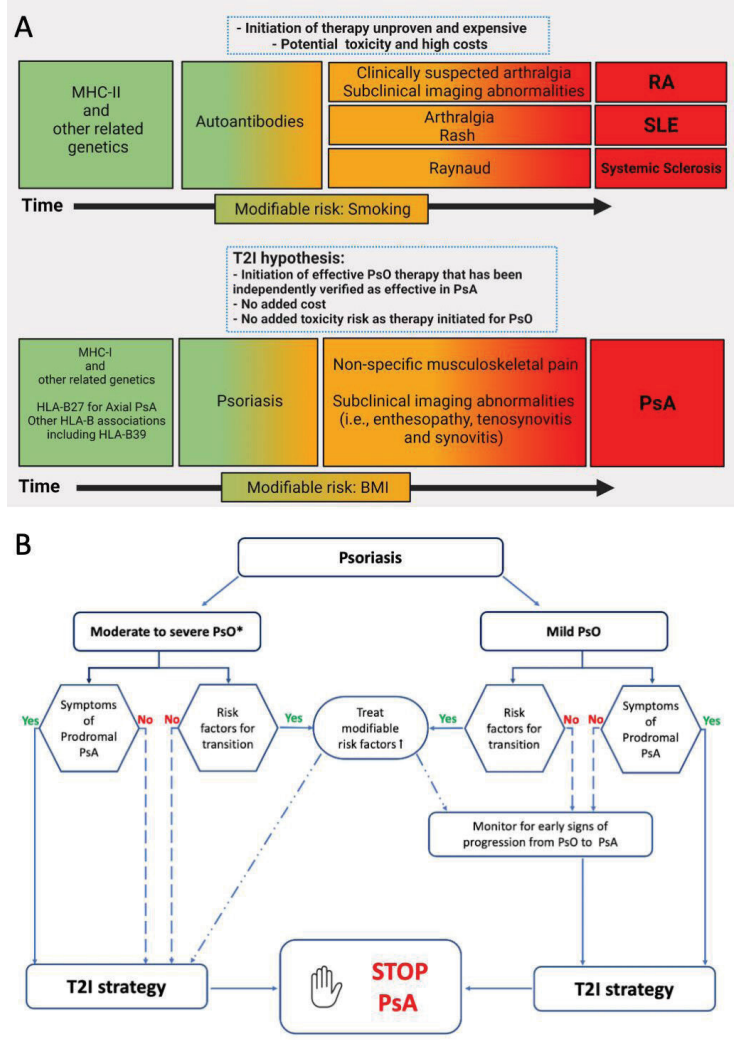

Figure 1 (A) Comparing autoimmune disease evolution to psoriatic arthritis (PSA) evolution. Unlike humoral immune-mediated autoimmune diseases where the autoantibodies that predate disease are a risk factor for disease that cannot be therapeutically manipulated at present, the psoriasis ( $\mathrm{PsO}$ ) biomarker is both a predictor of PsA and a target for therapy itself. This is a unique feature and means that the initiation of therapy does not increase risk of toxicity or costs providing the PsO is extensive enough to merit therapy that could intercept arthritis evolution. ${ }^{30-33}$ (B) The concept of treat to intercept (T2I) algorithm for interception of PsA in PsO patients.

* Moderate to severe PSO is defined as either extensive (body surface area involvement $>10 \%$ ), or as important to the patient: more limited PsO leading to significant impact on quality of life (eg, face/hand/feet/genital involvement). When patients have mild PSO but risk factors for PSA then systemic therapy for PSO would not ordinarily be initiated. However, risk factors for imminent PSA could make this group a potential target for therapy or T2I. BMI, body mass index; MHC, major histocompatibility complex; RA, rheumatoid arthritis.

interventions would be prescribed to otherwise healthy (at risk) subjects (figure 1). Different, interventions for preventing PsA in the presence of clinically active $\mathrm{PsO}$ would, if effective, mitigate the risks/benefits ratio considerably. Increasingly recognised shared immunepathological mechanisms between the skin and the enthesis-an early musculoskeletal key target lesion (figure 2) in PsA-are likely to provide a rationale for efficacy of $\mathrm{PsO}$ interventions beyond the skin level.

Therefore, several unique aspects around the potential for PsA prevention are distinguished from diseases like RA. First, several licensed systemic therapies for the treatment of $\mathrm{PsO}$ were independently verified as effective in established PsA. ${ }^{10}$ While the therapy of $\mathrm{PsO}$ included conventional DMARDs
(cDMARDs) initially, this evolved into the antitumour necrosis factor (TNF) agents about 15 years ago with these agents showing improved skin efficacy. ${ }^{11}$ In recent years, the interleukin 23 (IL23)/IL-17 axis cytokine blockade has been introduced to $\mathrm{PsO}$ where complete skin clearance has been reported in up to $50 \%$ of cases. ${ }^{10}$ Such efficacy, an acceptable safety profile and the lack of clinically relevant neutralising antibodies, more often encountered with the use of the anti-TNF blockers, positions the IL-23/IL-17 blockers as therapies that are both liked, tolerated and show even better long-term retention. All factors that auger well for continuous use of therapies that could prevent manifestation of PsA in PsO patients. Some small preliminary studies have hinted that the use of both c-DMARDs and bDMARDs may be associated with a lower incidence of PsA development compared with topical or phototherapy. ${ }^{12}$

In ARD, the impact of systemic treatment on the development of PsA in PsO patients was evaluated in a retrospective cohort of PsO patients. ${ }^{13-15}$ Gisondi et al and Acosta Felquer et al showed that PsO patients, without clinical evidence of PsA, treated with bDMARDs had a lower risk of PsA development compared with those treated with narrow-band ultraviolet light B (nb-UVB) phototherapy or those treated with topicals or without treatment. ${ }^{1314}$ Both studies found similar results in terms of incidence rates of PsA, (i.e., 1.2 and 1.6 cases per 100 patients/ year, respectively) and nail involvement as predictor of later PsA development. The role of biologics as possible interceptor of PsA development in $\mathrm{PsO}$ was also described in a recent study, published in another journal. ${ }^{16}$ In contrast, Meer et al, the third study on the topic published in this ARD issue, used an electronic health record database and found a higher incidence of PsA among PsO patients treated with bDMARDs than patients on oral or phototherapy. ${ }^{15}$ These results appear inconsistent with clinical practice, in fact the authors stated these findings should not be interpreted causally, i.e, it is common experience that bDMARDs do not cause PsA. The key message of Meer et al is to use caution in interpreting results from retrospective studies. Several confounders and sources of bias should be taken in consideration, such as confounding by indication and the protopathic bias. Furthermore, results could be different depending on the cohort analysed (eg, dermatology clinic-based population or population based) and the way the data were analysed.

Hence, in the topic of transition from PsO to PsA, retrospective studies should be considered as hypotheses generating, but findings need to be validated in prospective studies and randomised controlled trials with an adequate follow-up depending on the selected PsO population.

Factors including the severity of $\mathrm{PsO}$, nail involvement and family history of PsA are long-term predictors of PsA development, while the presence of arthralgia is a short-term predictor. ${ }^{3} 17$ These factors for the transition from PsO to PsA may assist researchers in definition of target populations at risk and adequate timing of follow-up periods for prospective transition studies. 


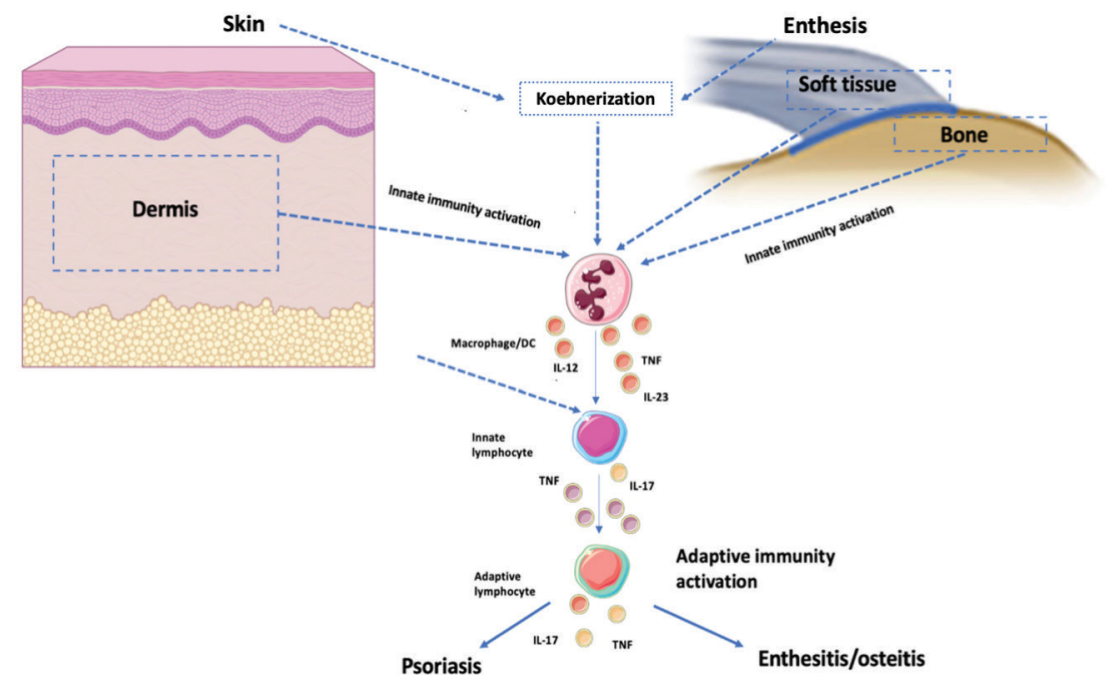

Figure 2 Emerging biological basis for the therapeutic prevention of PSA with drug use for PSO. When considering psoriasis ( $\mathrm{PsO}$ ) and PSA from the perspective of the enthesis, there is clear evidence for convergent paths from tissue microanatomy to immunological mechanisms. Both sites show microanatomical similarities including an avascular (epidermis and fibrocartilage zone respectively) and both are subject to Koebnerisation responses, whereby injury can trigger disease. Convergent immune homoeostasis mechanisms between both sites are increasingly recognised including resident myeloid cells capable of IL-23 production and the presence of both innate and adaptive T cells even in health including ILC3 and $\gamma \delta$ T-cells at both the skin and enthesis. Conventional T cells including CD4 and CD8 T-cells including tissue resident memory (TRM) cells are present at both sites. Also some therapies show similar efficacy between skin and joints with respect to pathognomonic dactylitic lesion resolution. Collectively, these provide a strong basis for PSA prevention in PSO treated cases. DC, dentritic cell; IL-23, interleukin 23; PSA, psoriatic arthritis; TNF, tumour necrosis factor.

In the 'PsO to PsA march', there is good evidence that the earliest stage of PsA in experimental models and latterly in humans is linked to early enthesitis with subsequent inflammation spreading to the synovium. ${ }^{18}$ In humans, $\mathrm{PsO}$ subjects without musculoskeletal complaints have a much greater burden of subclinical articular inflammation compared with healthy controls. ${ }^{19} 20$ The evolution towards PsA is associated with the development of synovitis and tenosynovitis, which is again linked to the synovio-entheseal complex. ${ }^{21}$ Ultrasound determined subclinical enthesopathy regresses under biological therapy in $\mathrm{PsO}$ subjects ${ }^{22}$ and likewise subclinical MRI determined synovitis also regresses under biological therapy, ${ }^{23}$ with both these studies providing mechanistic corroborative evidence that underpins the findings from the Gisondi et al and Acosta Felquer et al studies. ${ }^{13} 14$

\section{POTENTIAL THERAPY FOR PSA INTERCEPTION}

Noting the aforementioned arguments around the centrality of enthesitis it is noteworthy that methotrexate was thought not to work for enthesitis but is now endorsed in some quarters for that purpose. ${ }^{24}$ This raises the possibility that c-DMARDs that are less effective for established enthesitis may nevertheless have a role in preventing it. The anti-TNF agents work less efficiently for skin disease compared with the emergent IL-23/IL-17 inhibitors and it will be interesting to see whether there are any emergent differences between biological classes for possible PsA interception. $^{25} 26$ Furthermore axial PsA evolution may overlap with ankylosing spondylitis (AS) - a disease where IL-23 pathway blockade failed. ${ }^{27}$ However, in experimental models the pre-emptive use of IL-23 blockers was associated with the non-evolution of axial disease even though it could not treat established disease. ${ }^{28}$ Overall, this supports the idea that there may be broad protection with different cDMARD and bDMARD classes for the interception of PsA.

\section{BIOLOGICAL RATIONALE FOR PSA PREVENTION AND INTERCEPTION}

It is increasingly clear that there is a close connection between the immunopathogenesis of skin and joint disease in $\mathrm{PsO}$ and PsA with both the normal skin and enthesis sharing IL-23/IL-17 axis immunogenetics and innate as well as adaptive IL-23/17 lineage immune cells in healthy tissue. $^{2526}$ The emergent IL23/IL-17 axis blockers are associated with skin clearance in up to $50 \%$ of cases, however, responses in signs and symptoms of PsA (eg, American College of Rheumatology $20 \% / 50 \% / 70 \%$ response rates) are modest, which has been interpreted as a relative lack in depth of response in PsA. However, the clearance of dactylitis, the pathognomonic lesion of PsA, is reported up to $80 \%-90 \%$ of cases at 6 and 12 months. ${ }^{29}$ This illustrates a closer therapeutic connection between skin and joint than hitherto appreciated as does the similar responses of PsA to IL-17A, IL23 and TNF inhibitor class drugs.

\section{IMPLICATIONS}

Many questions remain. Might the prevention of PsA, which is one systemic feature of PsO, also have implications for prevention of other complications of $\mathrm{PsO}$ as for example ischaemic heart disease that appears to be more frequent in PsA subjects ? What is the impact of different modes of action of bDMARDs on the metabolic syndrome and its clinical consequences? The majority of PsA patients present with mild skin involvement and usually do not need a systemic treatment or a dedicated dermatological follow-up. The crux for this group is how to prevent/intercept PsA in PsO patients if biological therapies for skin disease with lower PASI scores would be based on a higher PsA risk (figure 1). These milder PsO cases lead to the new hypothesis of 'Treat the skin To Intercept PsA' (figure 1B) - a fascinating challenge in the next years. Moreover, the consideration of reduction of PsA development as new clinical outcome/endpoint in $\mathrm{PsO}$ clinical trials may be of specific importance, particularly in the subset of $\mathrm{PsO}$ patients at high risk for transition.

To summarise, our dermatological colleagues may have already ushered in the era of PsA prevention without additional toxicity or cost implications. Validating and refining and understanding this across the full spectrum of PsO including mild disease represents a new challenge.

Handling editor Gerd-Rüdiger R Burmester

Acknowledgements DMG and GDM are supported in part by the National Institute for Health Research (NIHR) Leeds Biomedical Research Centre, United Kingdom. 
Contributors Substantial contributions to the conception or design of the work: all authors; Drafting the work or revising it critically for important intellectual content: all authors; Final approval of the version to be published: all authors; Agreement to be accountable for all aspects of the work in ensuring that questions related to the accuracy or integrity of any part of the work are appropriately investigated and resolved: $D M G, A Z, A W, C B, G D M, A K$ and $D A$

Funding The authors have not declared a specific grant for this research from any funding agency in the public, commercial or not-for-profit sectors.

Disclaimer The views expressed are those of the authors and not necessarily those of the NHS, the NIHR or the Department of Health.

Competing interests None declared.

Patient and public involvement Patients and/or the public were not involved in the design, or conduct, or reporting, or dissemination plans of this research.

Patient consent for publication Not applicable.

Provenance and peer review Commissioned; externally peer reviewed.

(c) Author(s) (or their employer(s)) 2022. No commercial re-use. See rights and permissions. Published by BMJ.

$$
\text { D) Check for updates }
$$

To cite McGonagle DG, Zabotti A, Watad A, et al Ann Rheum Dis 2022:81:7-10.

Received 28 July 2021

Accepted 26 October 2021

Published Online First 22 November 2021

\section{SLinked}

http://dx.doi.org/10.1136/annrheumdis-2021-

219961

http://dx.doi.org/10.1136/annrheumdis-2021-

220865

http://dx.doi.org/10.1136/annrheumdis-2021 220761

Ann Rheum Dis 2022:81:7-10.

doi:10.1136/annrheumdis-2021-221255

\section{ORCID iDs}

Alen Zabotti http://orcid.org/0000-0002-0573-464X Abdulla Watad http://orcid.org/0000-0002-2390-6505 Andreas Kerschbaumer http://orcid.org/0000-00026685-8873

Daniel Aletaha http://orcid.org/0000-0003-2108-0030

\section{REFERENCES}

1 Perez-Chada LM, Haberman RH, Chandran V, et al. Consensus terminology for preclinical phases of psoriatic arthritis for use in research studies: results from a Delphi consensus study. Nat Rev Rheumatol 2021;17:238-43.

2 Nestle FO, Kaplan DH, Barker J. Psoriasis. N Engl J Med 2009:361:496-509.

3 Zabotti A, De Lucia O, Sakellariou G, et al. Predictors, risk factors, and incidence rates of psoriatic arthritis development in psoriasis patients: a systematic literature review and meta-analysis. Rheumatol Ther 2021. doi:10.1007/s40744-021-00378-w. [Epub ahead of print: 0110 2021].

4 Emery P, Kvien TK, Combe B, et al. Combination etanercept and methotrexate provides better disease control in very early ( $<=4$ months) versus early rheumatoid arthritis ( $>4$ months and $<2$ years): post hoc analyses from the comet study. Ann Rheum Dis 2012;71:989-92.

5 Regnell SE, Lernmark Åke. Early prediction of autoimmune (type 1) diabetes. Diabetologia 2017:60:1370-81

6 Gerlag DM, Raza K, van Baarsen LGM, et al. EULAR recommendations for terminology and research in individuals at risk of rheumatoid arthritis: report from the study Group for risk factors for rheumatoid arthritis. Ann Rheum Dis 2012;71:638-41.

7 Md Yusof MY, Psarras A, El-Sherbiny YM, et al. Prediction of autoimmune connective tissue disease in an at-risk cohort: prognostic value of a novel two-score system for interferon status. Ann Rheum Dis 2018;77:1432-9.

8 Skyler JS. Prevention and reversal of type 1 diabetes-past challenges and future opportunities. Diabetes Care 2015:38:997-1007

9 Zabotti A, Tinazzi I, Aydin SZ, et al. From psoriasis to psoriatic arthritis: insights from imaging on the transition to psoriatic arthritis and implications for arthritis prevention. Curr Rheumato/ Rep 2020;22:24.

10 Gossec L, Baraliakos X, Kerschbaumer A, et al. EULAR recommendations for the management of psoriatic arthritis with pharmacological therapies: 2019 update. Ann Rheum Dis 2020:79:700-12

11 Reich K, Nestle FO, Papp K, et al. Infliximab induction and maintenance therapy for moderate-to-severe psoriasis: a phase III, multicentre, double-blind trial. Lancet 2005:366:1367-74.

12 Solmaz D, Ehlebracht A, Karsh J, et al. Evidence that systemic therapies for psoriasis may reduce psoriatic arthritis occurrence. Clin Exp Rheumatol 2020:38:257-61.

13 Gisondi P, Bellinato F, Targher G, et al. Biological disease-modifying antirheumatic drugs may mitigate the risk of psoriatic arthritis in patients with chronic plaque psoriasis. Ann Rheum Dis 2022:81:66-71.

14 Acosta Felquer ML, LoGiudice L, Galimberti ML, et al. Treating the skin with biologics in patients with psoriasis decreases the incidence of psoriatic arthritis. Ann Rheum Dis 2022;81:72-7

15 Meer E, Merola JF, Fitzsimmons R, et al. Does biologic therapy impact the development of PSA among patients with psoriasis? Ann Rheum Dis 2022;81:78-84

16 Shalev Rosenthal Y, Schwartz N, Sagy I, et al. Psoriatic arthritis incidence among patients receiving biologic medications for psoriasis: a nested case control study. Arthritis Rheumatol 2021. doi:10.1002/art.41946. [Epub ahead of print: 23 Aug 2021]

17 Zabotti A, McGonagle DG, Giovannini I, et al. Transition phase towards psoriatic arthritis: clinical and ultrasonographic characterisation of psoriatic arthralgia. RMD Open 2019:5:e001067.

18 McGonagle D, Gibbon W, Emery P. Classification of inflammatory arthritis by enthesitis. Lancet 1998:352:1137-40.

19 Gisondi P, Tinazzi I, El-Dalati G, et al. Lower limb enthesopathy in patients with psoriasis without clinical signs of arthropathy: a hospital-based case-control study. Ann Rheum Dis 2008;67:26-30.

20 Zuliani F, Zabotti A, Errichetti E, et al. Ultrasonographic detection of subclinical enthesitis and synovitis: a possible stratification of psoriatic patients without clinical musculoskeletal involvement. Clin Exp Rheumatol 2019;37:593-9.

21 McGonagle D, Lories RJU, Tan AL, et al. The concept of a "synovio-entheseal complex" and its implications for understanding joint inflammation and damage in psoriatic arthritis and beyond. Arthritis Rheum 2007;56:2482-91.

22 Savage L, Goodfield M, Horton L, et al. Regression of peripheral subclinical enthesopathy in therapy-naive patients treated with ustekinumab for moderate-tosevere chronic plaque psoriasis: a fifty-two-week, prospective, open-label feasibility study. Arthritis Rheumatol 2019;71:626-31.

23 Kampylafka E, Simon D, d'Oliveira I, et al. Disease interception with interleukin-17 inhibition in high-risk psoriasis patients with subclinical joint inflammationdata from the prospective IVEPSA study. Arthritis Res Ther 2019;21:178.

24 Coates LC, Corp N, van der Windt DA, et al. Grappa treatment recommendations: an update from the 2020 grappa annual meeting. J Rheumato/ Supp/ 2021;97:65-6.

25 Watad A, Rowe H, Russell T, et al. Normal human enthesis harbours conventional CD4+ and CD8+ $T$ cells with regulatory features and inducible IL-17A and TNF expression. Ann Rheum Dis 2020;79:1044-54.

26 Bridgewood C, Sharif K, Sherlock J, et al. Interleukin-23 pathway at the enthesis: the emerging story of enthesitis in spondyloarthropathy. Immunol Rev 2020;294:27-47

27 Baeten D, Østergaard M, Wei JC-C, et al Risankizumab, an IL-23 inhibitor, for ankylosing spondylitis: results of a randomised, double-blind, placebo-controlled, proof-of-concept, dose-finding phase 2 study. Ann Rheum Dis 2018:77:1295-302.

28 Sieper J, Poddubnyy D, Miossec P. The IL23-IL-17 pathway as a therapeutic target in axial spondyloarthritis. Nat Rev Rheumatol 2019:15:747-57

29 Kerschbaumer A, Smolen JS, Dougados M, et al. Pharmacological treatment of psoriatic arthritis: a systematic literature research for the 2019 update of the eular recommendations for the management of psoriatic arthritis. Ann Rheum Dis 2020;79:778-86.

30 Winchester R, Minevich G, Steshenko V, et al. HLA associations reveal genetic heterogeneity in psoriatic arthritis and in the psoriasis phenotype. Arthritis Rheum 2012:64:1134-44.

31 Eder L, Chandran V, Pellett F, et al. Differential human leucocyte allele association between psoriasis and psoriatic arthritis: a family-based association study. Ann Rheum Dis 2012:71:1361-5.

32 Eder L, Polachek A, Rosen CF, et al. The development of psoriatic arthritis in patients with psoriasis is preceded by a period of nonspecific musculoskeletal symptoms: a prospective cohort study. Arthritis Rheumatol 2017:69:622-9.

33 Zabotti A, De Lucia O, Sakellariou G, et al. Predictors, risk factors, and incidence rates of psoriatic arthritis development in psoriasis patients: a systematic literature review and meta-analysis. Rheumatol Ther 2021:8:1519-34. 